DOI: https://doi.org/10.47405/mjssh.v5i5.394

\begin{tabular}{|c|c|}
\hline sist & Malaysian Journal of Social Sciences and Humanities (MJSSH) \\
\hline Malaysian Journal of & Volume 5, Issue 5, May 2020 \\
\hline (MJ-SSH) & e-ISSN : 2504-8562 \\
\hline & $\begin{array}{l}\text { Journal home page: } \\
\text { www.msocialsciences.com }\end{array}$ \\
\hline
\end{tabular}

\title{
Meneroka Kaedah Pengajaran Guru Cemerlang Pendidikan Seni Visual Selangor (GCPSV): Satu Kajian Kes
}

\author{
Roslina Binti Mohd Nor'1, Nik Mohd Rahimi Bin Nik Yusoff' ${ }^{1}$, Hamdzun Bin Haron \\ 1 Fakulti Pendidikan, Universiti Kebangsaan Malaysia (UKM) \\ Correspondence: Roslina Binti Mohd Nor (razeqhakimey@gmail.com)
}

\begin{abstract}
Abstrak
Kajian ini bertujuan untuk meneroka kaedah pengajaran guru Pendidikan Seni Visual di Selangor. Kajian kualitatif menggunakan reka bentuk kajian kes. Lima orang guru Pendidikan Seni Visual yang dipilih secara rawak bertujuan sebagai peserta kajian. Data dikumpul melalui kaedah temu bual, pemerhatian dan analisis dokumen. Data dianalisis secara trangulasi iaitu data temu bual akan disokong dengan data pemerhatian dan analisis dokumen. Analisis data kualitatif dirumuskan bahawa terdapat tujuh tema ditemui yang banyak digunakan oleh guru Pendidikan Seni Visual dalam pengajaran dan pemudah cara $(\mathrm{PdPc})$ mereka iaitu persediaan rangcangan pengajaran $\mathrm{PdPc}$, menyediakan set induksi, mengurusan bilik darjah ketika pdpc, mengamalkan pelbagai pedagogi $\mathrm{PdPc}$, membuat penilaian semasa PdPc, membuat kesimpulan PdPc dan menggunakan pelbagai bahan bantu mengajar. Implikasi kajian ini adalah untuk menjadi guru cemerlang Pendidikan Seni Visual, seseorang guru Pendidikan Seni Visual itu perlu memiliki tujuh ciri PdPc seperti yang dimiliki oleh guru cemerlang Pendidikan Seni Visual dalam kajian ini.
\end{abstract}

Kata kunci: kaedah pengajaran, guru cemerlang pendidikan seni visual, kajian kes

\section{Exploring Teaching Method of Selangor Arts Excellent Teacher: A Case Study}

\begin{abstract}
This study aimed to explore the teaching method of Arts excellent teachers in Selangor. Qualitative study using the case study design. Five selected Visual Arts educational teachers are intended to be a research participant. Data is collected through interview, observation, and document analysis methods. Data were analyzed by trangulation in which the data will be supplemented with interviews, observation data and document analysis. Analysis of qualitative data concluded that there are seven major themes encountered are widely used by Arts execellent teachers in their T\&L, which the teaching of T\&L, providing induction sets, managing classrooms while PdPc, practicing a variety of pedagogical T\&L, making assessments during T\&L, concluded the T\&L and using various materials of teaching. The implications of this study are to be appointed as Art teacher it is necessary to have seven properties owned by the T\&L the Arts excellent teacher studied.
\end{abstract}

Keywords: teaching method, art excellent teacher, case study 


\section{Pengenalan}

Keberkesanan pengajaran dan pembelajaran di dalam kelas bergantung kepada penguasaan pengetahuan pedagogi ilmu kandungan guru terhadap sesuatu mata pelajaran. Guru perlu mempunyai tahap profesionalisme yang tinggi dan berkualiti (Ong, 2017). Oleh itu inisiatif pembangunan profesion keguruan dalam bentuk pembinaan ilmu dan kemahiran pengajaran dan pemudah cara (PdPc), pengurusan, penyampaian, pengawasan, penyeliaan, penilaian, kerohaniaan dan keinsanan dan kebajikan dalam kalangan warga pendidik perlu dimantapkan (Ong, Zambri \& Mohd Izham 2017). Hal ini dapat membantu proses PdPc dilaksanakan secara berterusan, rasional dan ilmiah, berpandukan informasi dan ilmu pengetahuan.

Berdasarkan tinjauan literatur terhadap kajian-kajian lepas terdapat banyak kajian berkenaan kaedah pengajaran guru mata pelajaran selain Pendidikan Seni Visual (PSV) telah dikaji oleh pengkaji tempatan seperti mata pelajaran Bahasa Arab oleh Ainon (2016) dan Aisyah (2017), Bahasa Iban oleh Magdeline (2014) dan PSV oleh Ong (2018). Namun begitu, kajian-kajian tempatan berkaitan dengan kaedah PdPc guru PSV tidak pernah dijalankan oleh pengkaji lain sebelum ini. Kajian tentang PSV yang lepas banyak berfokus kepada kepentingan PSV dalam pendidikan, kemahiran serta aprisiasi seni visual. Justeru, satu kajian yang menjurus kepada kaedah pdp guru cemerlang PSV diperlukan. Hal ini bertujuan agar dapat memberi gambaran sebenar kepada guru PSV untuk menjadi seorang guru PSV yang berkualiti dan mampu meningkatkan pencapaian pelajarnya.

Dalam meneroka kaedah pengajaran guru dalam kajian ini, kajian lepas mendapati guru mengakui kurangnya penguasaan terhadap pengurusan bilik darjah, kawalan kelas, interaksi dan komunikasi, strategi am pengajaran serta aspek penilaian dan refleksi pengajaran (Ong, 2017). Kurangnya penguasaan bilik darjah guru-guru terutama sekali mata pelajaran PSV yang melibatkan kemahiran praktik akan mengganggu kelancaran PdPc dalam bilik darjah. Gangguan kelancaran PdPc ini mengakibatkan pelajar tidak dapat memberi perhatian semasa guru mengajar. Dalam kajian Choong (2009) mendapati beberapa masalah yang sering timbul dikalangan pelajar semasa berada di bilik darjah adalah tidak memberikan tumpuan kepada pengajaran yang disampaikan guru, sebaliknya cenderung berbual dengan rakan lain ataupun berkomunikasi secara tidak lisan serta pelajar kerap tidak menyelesaikan kerja rumah yang diberikan oleh guru. Oleh itu kajian ini di perlukan sebagai panduan kepada guru PSV untuk meningkatkan lagi kualiti pengajaran dan pembelajaran mereka di dalam kelas.

Tujuan kajian ini adalah untuk meninjau ciri cemerlang secara mendalam dan menyeluruh dari segi kaedah pengajaran yang dimiliki oleh lima orang guru cemerlang PSV (GCPSV) di Selangor. Secara khusus, objektif kajian ini adalah untuk: Meneroka bagaimana GCPSV mengaplikasikan bentuk kaedah pengajarannya di dalam bilik darjah.

\section{Metod Kajian}

Dalam kajian ini, penyelidikan kualitatif dipilih dengan menggunakan kaedah kajian kes. Kes yang dimaksudkan dalam kajian ini ialah pengetahuan pedagogi ilmu kandungan yang dimiliki oleh GCPSV. Penyelidikan kualitatif merujuk kepada kajian yang dihasilkan daripada data deskriptif yang diperoleh berdasarkan catatan atau pengucapan dan pemerhatian terhadap tingkah laku seseorang (Taylor @ Bogdan, 2015). Menurut Chow (2005), pendekatan kualitatif adalah satu proses inkuiri untuk meneroka permasalahan sosial. Pengkaji cuba membina gambaran holistic terhadap sesuatu situasi, peristiwa atau fenomena yang kompleks. Bentuk kajian ini juga adalah sebagai usaha untuk mendapatkan kefahaman yang mendalam tentang sesuatu perkara atau situasi dengan mengambil kira semua sifat atau tingkah laku yang terlibat. Dengan cara ini, keadaan sesuatu fenomena sebanar dapat difahami dan diterangkan dengan jelas dan tidak berasaskan andaian semata-mata (Merriam 2009).

Penyelidikan kualitatif tidak bertujuan untuk membuat justifikasi terhadap sesuatu situasi atau kes sebaliknya untuk memahami proses tentang bagaimana seseorang memberi makna terhadap kes yang dikaji (Chow, 2005). Rasional pemilihan penyelidikan kualitatif adalah untuk menambah pengetahuan, 
lebih memahami tingkah laku manusia dan pengalaman mereka (Bogdan \& Biklen, 2007). Oleh itu, pendekatan penyelidikan ini sesuai untuk meneroka dan memahami pandangan peserta kajian terhadap isu-isu dan proses yang berlaku dalam situasi yang sebenar (Chow, 2005).

Menurut Yin (2014), kajian kes adalah satu penyelidikan yang mengkaji fenomena yang terjadi dalam konteks sebenar, khususnya bila terdapat lompang antara fenomena dan konteks yang mempunyai bukti yang kurang jelas. Oleh itu, dalam kajian ini pendekatan kajian kes dipilih kerana ia adalah sesuai dengan tujuan kajian yang ingin mendapatkan kefahaman yang mendalam tentang bentuk pengetahuan pedagogi ilmu kandungan yang dimiliki oleh guru-guru PSV sekolah menengah. Kaedah ini melalui penelitian terhadap pengetahuan ilmu kandungan, pengetahuan pedagogi khusus, pengetahuan pedagogi am dan pengetahuan konteks, dengan menggunakan kaedah temu bual, pemerhatian, dan analisis dokumen.

Protokol temu bual merupakan alat yang digunakan untuk membantu mengumpul data. Ia dibina dengan menggunakan solalan untuk menjawab persoalan kajian. Pengkaji telah menggunakan protokol temubual. Alat perakam audio digital telah digunakan bagi merakam temu bual. Kaedah ini dapat memberi fokus kepada pengalaman yang diceritakan oleh peserta kajian dan soalan yang mengarah kepada fokus kajian.

Data dari pemerhatian digunakan untuk mengesahkan data temu bual. Menurut Maxwell (2005), pemerhatian memberi pertimbangan yang berguna selain sesi temu bual dengan membenarkan pengkaji membuat perbandingan persamaan dan perbezaan di antara perkara-perkara yang timbul semasa temu bual dijalankan.

Di samping temu bual dan pemerhatian, kaedah analisis dokumen digunakan bagi menyokong dapatan temu bual. Analisis dokumen dipilih sebagai satu cara untuk mengumpulkan data kerana menurut Bogdan dan Biklen (2007), nota atau catatan guru adalah salah satu dokumen peribadi yang yang dapat menggambarkan tindakan, pengalaman dan kepercayaan mereka. Merriam (1998) menyatakan bahawa dokumen peribadi adalah sumber data yang boleh dipercayai berkaitan dengan sikap, kepercayaan dan pandangan seseorang. Jenis dokumen yang diteliti dan dianalisis semasa di sekolah termasuklah rancangan pengajaran harian, rekod kemajuan pelajar, rekod kehadiran pelajar, BBM dan hasil kerja pelajar. Sekolah yang dipilih ialah sekolah yang terdapat guru PSV yang dikaji berdasarkan kriteria yang ditetapkan.

Populasi kajian terdiri daripada semua guru PSV sekolah menengah kerajaan di Selangor. Oleh sebab kajian ini hanya kajian pelbagai kes, maka pengkaji menggunakan persampelan bertujuan, iaitu kelompok peserta yang mewakili populasi yang hendak dikaji dikenal pasti dan semua aktiviti dalam kelompok tersebut diambil kira sebagai sampel (Sabitha 2005). Oleh itu, pengkaji mengenal pasti sekolah-sekolah menengah kerajaan yang mempunyai guru cemerlang PSV. Selain itu, kos perbelanjaan dan batas masa juga perlu diambil kira kerana kajian ini melibatkan kajian kualitatif yang memerlukan kos perbelanjaan yang tinggi dan jangka masa yang lama untuk disiapkan.

Data ini dianalisis secara triangulasi. Menurut Wiersma (1991), triangulasi antara data merupakan salah satu cara untuk menjadikan data kualitatif mempunyai kepercayaan yang tinggi. Pengkaji menggunakan triangulasi data temu bual ini dengan data pemerhatian dan analisis dokumen bagi mengukuhkan kebolehpercayaan data dan tema yang dibina. Ia merupakan satu teknik kajian yang menggunakan dua atau lebih kaedah dalam kutipan data untuk mengkaji tingkah laku manusia (Cohen, Manion \& Morrison, 2000). Proses ini melibatkan sokongan bukti daripada sumber berbeza dalam usaha memahami dengan lebih lanjut satu-satu tema atau perspektif (Creswell, 1998). 


\section{Dapatan Kajian}

\section{Latar Belakang Peserta Kajian}

Lima orang guru PSV sekolah menengah yang menepati kriteria pemilihan kes yang dikaji telah dipilih sebagai peserta kajian. Kriteria yang ditetapkan ialah guru tersebut hendaklah yang mengajar PSV tingkatan 4 atau 5 atau kedua-duanya sekali di sekolah kebangsaan seliaan Kementerian Pendidikan Malaysia (KPM). Manakala ciri-ciri demografi peserta kajian diringkaskan dalam jadual 1, terdapat lima orang peserta kajian yang terdiri daripada guru-guru cemerlang PSV yang mengajar tingkatan 4 atau 5 di lima buah sekolah di Hulu Langat, Selangor. Sebagai memenuhi ciri kerahsiaan peserta kajian yang terlibat, guru-guru ini dilabelkan sebagai GCPSV1, GCPSV2, GCPSV3, GCPSV4 dan GCPSV5, masing-masing mewakili Guru Cemerlang PSV 1, Guru Cemerlang PSV 2, Guru Cemerlang PSV 3, Guru Cemerlang PSV 4 dan Guru Cemerlang PSV 5. Pengekodan ini dilakukan sebagai langkah memenuhi prinsip nonmaleficence yang menuntut supaya apa jua aktiviti kajian yang dijalankan hendaklah tidak membahayakan orang yang dikaji walaupun dapat memberi manfaat kepada orang lain.

Jadual 1: Profil Peserta Kajian

\begin{tabular}{|c|c|c|c|c|}
\hline $\begin{array}{l}\text { Peserta } \\
\text { kajian }\end{array}$ & umur & Bidang & Ikhtisas & $\begin{array}{l}\text { Tempoh } \\
\text { perkhidmatan }\end{array}$ \\
\hline GCPSV1 & 34 tahun & Seni lukis seni reka (Diploma \& Degree) & KPLI & 9 tahun \\
\hline GCPSV2 & 38 tahun & $\begin{array}{l}\text { Fotografi (diploma) } \\
\text { PSV (degree) }\end{array}$ & KPLI & 12 tahun \\
\hline GCPSV3 & 44 tahun & $\begin{array}{l}\text { Seni Lukis Seni Reka (Diploma) } \\
\text { Seni reka seni lukis (Degree) }\end{array}$ & $\begin{array}{l}\text { Diploma } \\
\text { pendidikan }\end{array}$ & 14 tahun \\
\hline GCPSV4 & 45 tahun & $\begin{array}{l}\text { Bidang printing teknologi (Degree) } \\
\text { Seni (Diploma) }\end{array}$ & KPLI & 15 tahun \\
\hline GCPSV5 & 39 tahun & $\begin{array}{l}\text { Seni reka grafik (Degree) } \\
\text { Seni visual (Diploma) }\end{array}$ & KPLI & 10 tahun \\
\hline
\end{tabular}

\section{Meneroka Bentuk Kaedah PdPc di dalam Bilik Darjah}

Kajian kes ini dilaksanakan ke atas lima orang peserta kajian yang telah bersetuju untuk melibatkan diri dalam kajian ini secara sukarela. Kelima-lima orang peserta kajian ini berada di lokasi kajian yang berbeza. Dalam fasa kedua ini, dapatan kajian dibentang dengan memberikan huraian tentang latar belakang lokasi kajian, peserta kajian dan dapatan yang menjawab setiap persoalan kajian.

Data diproses mengikut cadangan langkah-langkah sintesis bagi kaedah analisis kandungan (content analysis) mengikut Miles \& Huberman (1994) melalui tiga langkah prosedur iaitu penyaringan data, membuat kesimpulan dan penyemakan dalam menentukan pembentukan kategori atau tema. Ringkasan kategori atau tema dan subkategori atau subtema disenaraikan dalam jadual 2 bagi komponenkomponen seperti di bawah. Dalam kajian ini pengkaji meneroka bentuk kaedah PdPc di dalam bilik darjah dengan 4 tema utama iaitu:

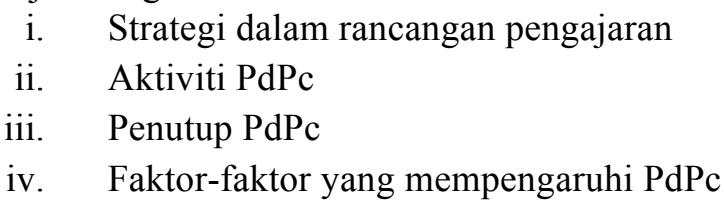


DOI: https://doi.org/10.47405/mjssh.v5i5.394

Jadual 2: Senarai kategori/tema dan subkategori/subtema

\section{Strategi dalam pengajaran}

a) Pembelajaran kontekstual

b) Pembelajaran masteri

c) Pembelajaran Kontekstual

d) Teknologi maklumat dan ICT

e) Kajian masa depan

2. Amalan GCPSV dalam PdPc

a. Set induksi

b. Aktiviti PdPc

Pemilihan aktiviti-aktiviti mengikut tahap kemahiran pelajar

Kesukaran dan miskonsepsi

Kesulitan dalam mengajar

PSV

3. Penutup PdPc

Penambahbaikan berterusan

4. Faktor-faktor yang mempengaruhi PdPc

\begin{tabular}{|c|c|c|c|c|}
\hline GCPS & GCPS & GCPS & GCPS & GCPS \\
\hline V1 & V2 & V3 & V4 & V5 \\
\hline I & I & I & I & I \\
\hline I & I & I & I & I \\
\hline I & I & I & I & I \\
\hline I & I & I & I & I \\
\hline I & I & I & I & l \\
\hline I & I & l & I & I \\
\hline I & I & I & I & l \\
\hline I & l & I & I & I \\
\hline I & l & l & I & I \\
\hline I & I & / & l & I \\
\hline
\end{tabular}

\section{Strategi dalam Pengajaran}

Dapatan kajian menunjukkan semua guru PSV mengamalkan strategi perancangan pengajaran dalam rancangan pengajaran dalam kelas. Dapatan temu bual dalam kajian ini mendapati guru PSV mengatur strategi dalam rancangan pengajaran mereka. Guru-guru PSV, mendapati telah merancang strategi dalam PdPc mengikut kesesuaian pelajar serta dapat menarik minat dan perhatian pelajar. Guru PSV juga telah membuat rancangan pengajaran harian dengan rapi, sistematik dan kreatif agar pembelajaran tidak membosankan dan objektif pengajaran akan tercapai. Terdapat banyak strategi yang digunakan dan diaplikasikan oleh guru PSV semasa proses PdPc seperti:
i. Pembelajaran kontekstual
ii. Pembelajaran masteri
iii. Pembelajaran Kontekstual
iv. Teknologi maklumat dan ICT
v. Kajian masa depan.

\section{Pembelajaran Kontekstual}

Sebahagian besar guru PSV yang ditemu bual berpendapat bahawa cara terbaik yang sering dilakukan untuk memotivasikan pelajar di dalam bilik darjah semasa PdPc adalah dengan mengaitkan mata pelajaran PSV dengan kerjaya mereka di masa hadapan.

“..saya kata ye la bila belajar ni kita tak nampak sangat tapi bila dah keluar satu per satu kalau betul awak masuk dalam bidang ni awak akan nampak benda ni semua berguna kepada diri awak, lepas tu bukannya apply di tempat kerja sahaja ye la dia akan apply dekat diri sendiri," - GCPSV5

GCPSV2 memotivasikan pelajar-pelajarnya dengan cara minta bantuan dari bekas pelajar GCPSV2 yang telah berjaya dalam bidang PSV untuk memberi nasihat dan dorongan kepada pelajar-pelajar.

“..selalunya motivasi, saya perlukan juga bantuan.........saya cuba cari balik mungkin pensyarah ataupun ex-student, saya selalu contact balik dengan bekas- 
DOI: https://doi.org/10.47405/mjssh.v5i5.394

bekas pelajar yang dah berjaya dalam bidang seni datang balik kat sekolah cuba cerita balik apa pentingnya seni..," - GCPSV2

\section{Pembelajaran Masteri}

Berlainan pula dengan GCPSV3 dalam temu bualnya mendapati pelajar yang lemah akan diberi penumpuan yang lebih dengan memberi satu contoh karya dan pelajar membuat aktiviti secara individu

"kalau pelajar lemah saya bagi seorang satu contoh catan lepas tu pelajar akan melukis dan mencatan."- GCPSV3

Sementara pelajar yang pandai pula melakukan aktiviti secara berkumpulan.

"aktiviti-aktiviti tu berdasarkan kepada pelajar, pelajar berkumpulan. kalau pelajar yang depan secara berkumpulan” - GCPSV3

Oleh yang demikian, perancangan pengajaran untuk kelas yang berlainan bagi tingkatan yang sama (tingkatan 4 sebagai contoh) tidak akan sama sepenuhnya kerana guru GCPSV3 akan membuat pengubahsuaian terhadap rancangan pelajaran tersebut mengikut kesesuaian tahap dan pengetahuan sedia ada pelajar mengikut kelas.

\section{Teknologi maklumat dan ICT}

Dapatan kajian melalui pemerhatian dan temu bual mendapati pembelajaran menggunakan teknologi maklumat dan ICT diaplikasikan oleh guru dalam PdPc PSV melalui projek kolaboratif dengan menggunakan komputer, termasuklah mencari bahan melalui internet, Aktiviti berfikrah, pelajar mengkaji sesuatu bahan seni menggunakan ICT dan sebagainya. Contoh petikan daripada temu bual yang dijalankan terhadap GCPSV4.

"kalua ICT sekali sekala kita bagi tugasan suruh cari bahan ke, nak taip ke. Kadang-kadang bawak pelajar ke makmal komputer untuk cari bahan. Kenalkkan animasi tu macam mana ha” - GCPSV4

\section{Kajian Masa Depan}

Dalam aktiviti kajian masa depan, pelajar digalakkan menggunakan pemikiran kritis dan kreatif untuk meninjau perubahan keadaan dari masa dahulu ke masa sekarang dan seterusnya membuat ramalan tentang keadaan yang mungkin berlaku pada masa depan. Pedagogi ini berpusatkan pelajar dan menggabungjalinkan PSV dengan pelbagai bidang yang lain seperti pendidikan alam sekitar, sains dan lain-lain. Dapatan kajian melalui temu bual dengan guru PSV mendapati mereka mengamalkan aktiviti kajian masa depan. Ia adalah satu pendekatan pengajaran untuk mendidik pelajar agar lebih prihatin terhadap sesuatu perkara atau isu yang berlaku pada masa lampau, masa kini, dan masa depan. Melalui pemerhatian, guru-guru PSV dalam kajian menyedari tentang kepentingan kajian masa lampau kepada pelajar. Contohnya, pelajar diberi tugasan menghasilkan dan mencipta reka bentuk kereta national, menghasilkan kerusi pelbagai guna dan sebagainya seperti yang dilakukan oleh GCPSV1. Jadi pelajar akan berfikir jauh ke hadapan memikirkan rumah idaman mereka.

\section{Amalan GCPSV dalam PdPc}

Dapatan kajian melalui pemerhatian dan temu bual mendapati amalan GCPSV dalam PdPc dibahagi kepada set induksi, pemilihan aktiviti PdPc, penutup PdPc dan faktor yang mempengaruhi PdPc. 


\title{
Amalan Set Induksi
}

Dalam temu bual yang dijalankan, didapati bahawa guru PSV menjalankan aktiviti mengikut kreativiti masing-masing. Sebagai contoh GCPSV1 menyediakan aktiviti set induksi dalam bilik darjah.

\begin{abstract}
"biasanya saya cerita dulu dengan budak macam tanya kenal tak tokoh catan, saya sebut la nama apa pencatan kita, macam luar negara ke dalam negara ke, ataupun nama-nama pernah pergi galeri ke saya tanya pengalaman dia orang lepas tu baru kita masuk." - GCPSV1
\end{abstract}

GCPSV5 mempunyai perancangan aktiviti berdasarkan keperluan PdPc bersesuaian dengan sukatan pelajaran PSV. Sebagai contoh, beliau mengajar tajuk catan, aktiviti yang dirancang adalah melalui proses-proses menghasilkan karya catan seperti aktiviti lakaran, pemilihan penggunaan bahan, bancuhan warna dan sebagainya

\section{Amalan Pemilihan Aktiviti Pdpc}

Bagi meningkatkan kefahaman dan minat pelajar dalam PdPc yang dijalankan, pemilihan aktiviti dalam bilik darjah perlulah bersesuaian dengan pelajar. Banyak faktor yang harus dipertimbangkan sebelum menjalankan aktiviti. Oleh itu GCPSV mengamalkan membuat pemilihan aktivti PdPc seperti berikut:

\section{i) Aktiviti Mengikut Tahap dan Kemahiran Pelajar}

GCPSV3 contohnya membuat aktiviti mengikut tahap dan kemahiran pelajar. Bagi pelajar tahap tinggi, aktiviti demonstrasi dari pelajar yang mahir dan berbakat dilakukan bagi memvariasikan aktiviti dan kaedah PdPc dalam kelas.

"kalau cara lain tu saya suruh pelajar yang buat demo kepada kawan, kawan buat demo, andai kata catan tu pemandangan air terjun, so macam ada kumpulan buat demo untuk warnakan catan batu-batu, okay kumpulan lain buat pokok jadi saya buat secara berkumpulan" - GCPSV3

Begitu juga dengan GCPSV1, merancang aktiviti mengikut kesediaan dan tahap pelajar. Kelas pelajar tahap rendah dan sederhana, GCPSV akan menjalankan aktiviti lebih mudah, sementara kelas pelajar tahap tinggi aktiviti yang di lakukan lebih mencabar.

"kalau kelas yang hujung tu saya bagi aktiviti yang simple sahaja supaya boleh budak ikut." - GCPSV1

"merancang aktiviti, macam kelas yang okay sikit ni saya bagi la latihan yang advance sikit"- GCPSV1

\section{ii) Kesukaran dan miskonsepsi}

Guru-guru PSV menyatakan pendapat yang berbeza tentang kesukaran dan miskonsepsi semasa menjalankan PdPc dalam bilik darjah.

Guru GCPSV2 menganggap kesukaran yang dihadapi ketika menjalani aktiviti dalam kelas adalah melukis gambar realistik kerana pelajar tidak sabar dan tidak yakin untuk menghasilkan karya dengan baik.

"yang pertama bila nak lukis gambar realistik, tu memang susah tapi nak dapatkan real tu dia orang tak sabar" - GCPSV2 
"dia orang tak yakin contohnya bila buat satu kelopak sahaja dia nak cepat sahaja nak buat kelopak kedua dia tak fokus dia tak detail." - GCPSV2

Bagi GCPSV2 antara aktiviti yang agak susah untuk dilaksanakan dalam bilik darjah adalah perkembangan idea.

"lepas tu kedua yang susah bila nak kembangkan idea bila dia dah lukis gambar yang satu tu nak kembangkan jadi olahan yang simple yang bentuk grafik ke. ha yang tu pun susah" - GCPSV2

\section{iii) Kesulitan dalam mengajar PSV}

Guru-guru PSV menghadapi beberapa kesulitan dalam pengajaran seperti pelajar tidak berkemahiran dalam seni, pelajar tidak membawa bahan untuk pembelajaran, pelajar takut untuk mencuba dan tidak berminat dalam PSV.

Bagi GCPSV1, tajuk yang sukar diajar ialah lukisan potret.

"lukisan potret kot, yang susah nak ajar pada saya la." - GCPSV1

Trangulasi yang dijalankan melalui memerhatikan mendapati kebanyakan kelas PSV merupakan kelaskelas prestasi rendah dalam akademik dan ada di antara mereka menghadapi masalah disiplin di sekolah GCPSV4. Masalah ini bukan sahaja dihadapi oleh guru PSV, bahkan guru mata pelajaran lain juga. Pelajar tidak berminat belajar dan tidak fokus dengan pelajaran. Trangulasi melalui dokumen mendapati ada juga segelintir pelajar yang berprestasi rendah dalam akademik tetapi mempunyai bakat dalam seni dan berminat untuk belajar. Namun begitu jumlahnya tidak ramai. Melalui pemerhatian didapati adakalanya pelajar-pelajar ini mendapat gangguan daripada rakan sekelas ketika sesi pembelajaran.

Melalui trangulasi dokumen pakej mata pelajaran daripada sekolah GCPSV1, GCPSV2, GCPSV3, GCPSV4 dan GCPSV5, pelajar yang tidak berminat dengan mata pelajaran PSV adalah "pelajar mangsa sistem persekolahan" yang menyediakan pakej yang tidak selari dengan kehendak dan minat pelajar. Mata pelajaran PSV digabungkan dengan kelas mata pelajaran tasauwur, ekonomi, dan sebagainya.

\section{iv) Penambahbaikan Berterusan}

Penambahbaikan berterusan untuk pelajar secara berterusan perlu dalam menjalankan aktiviti dan kaedah pengajaran dalam mata pelajaran PSV dengan menjadikan mata pelajaran PSV itu mudah. Untuk menjadikan ia mudah dipelajari, guru sebagai penunjuk cara haruslah mempunyai kemahiran menarik perhatian pelajar dengan menunjukkan keindahan dalam seni itu sendiri. Sebagai contoh GCPSV5:

"sebagai cikgu ni sebagai penunjuk cara, memang kena tarik la, tunjuk cara tu kita tunjukkan sesuatu tu biar nampak menarik, cantik, jadi time tu la kalau dia minat dia nak buat" - GCPSV 5

Bagi GCPSV5 juga apabila timbul minat pelajar dalam PSV, mudah bagi mereka untuk pelajari seni itu sendiri.

“mudah sebab satunya minat la kan, bila benda tu dia dah minat dia jadi mudah"

Bagi GCPSV1, GCPSV3 dan GCPSV4 pula dalam temu bualnya mendapati mereka sentiasa memberi latihan bagi meningkatkan lagi pencapaian pelajar dan PdPc dalam bilik darjah. 
DOI: https://doi.org/10.47405/mjssh.v5i5.394

"kalau saya biasanya, ye la potret susah juga bagi saya, pada saya perlu praktis, satu lagi kalau macam untuk permulaan tu saya bagi pelajari edaran, bahan yang dah fotostat asas muka orang ka untuk tiru waktu mua-mula" - GCPSV1

GCPSV1 dan GCPSV5 menekankan kemahiran asas sebagai cara mengatasi kesukaran pelajar untuk belajar.
"saya kalau mula-mula belajar tu kemahiran asas seni tu saya memang tekankan dia mesti tahu asas semua unsur dan prinsip kan, tengok basic balik baru dia boleh buat satu karya yang bagus, kalau dia tak ada benda-benda tu susah la, lagi satu kemahiran la dia kena selalu praktis lagi." - GCPSV1
"saya tekankan, satu kemahiran, kemahiran lepas tu pengetahuan dalam bidang seni saya kata ye la bila belajar ni kita tak nampak sangat tapi bila dah keluar satu per satu kalau betul awak masuk dalam bidang ni awak akan nampak benda ni semua berguna kepada diri awak, lepas tu bukannya apply di tempat kerja sahaja ye la dia akan apply dekat diri sendiri, baik juga ye la semua nak cantik, tu saya kata nak cantik, nak lawa, bukan bidang seni ke semua tu saya ka? macam fesyen." - GCPSV5

Penambahbaikan berterusan untuk guru adalah perlu walaupun mereka adalah guru cemerlang. Contohnya dalam subjek kajian ini, guru PSV sering menghadiri kursus dan bengkel PSV sebagai penambahbaikan secara berterusan kerana ia banyak memberi kesan yang positif kepada corak pengajaran dan pembelajaran guru-guru. Mereka dapat berkongsi kemahiran sesama guru. Dengan cara sebegini, guru-guru akan dapat membaiki dan menambah baik corak pengajaran dan kemahiran sedia ada guru PSV. Penambahbaikan secara beterusan terhadap pelajar pula adalah dengan memberi latihan yang secukupnya mengikut kemahiran dan kesediaan pelajar.

\section{Amalan Penutup PdPc}

Dalam perancangan pengajaran, penyediaan bahan bantu mengajar untuk PSV perlu diutamakan. Bahan bantu mengajar iaitu peralatan melukis amat penting untuk menjamin PdPc amali berjalan lancar. GCPSV5 sebelum menamatkan pengajaran, beliau meminta dan mengingati pelajar untuk membawa peralatan PSV seminggu awal dari tarikh penggunaan BBM tersebut.

"salah satunya penyediaan bahan-bahan, ha saya mamang preparer macam minggu lepas saya buat batik ikat jerlon tu, prepare bahan dari segi tisu dengan getah dengan warna" - GCPSV5

Sesi apresiasi biasanya dilakukan oleh guru PSV pada penamat PdPc sesuatu sesi bagi membolehkan pelajar membuat penilaian dan perasaan terhadap karya yang mereka hasilkan. Sesi ini juga merupakan satu penghargaan kepada hasil seni pengkarya. Ia dapat membentuk sikap, minat dan kebolehan pelajar. Melalui temu bual yang dijalankan mendapati semua GCPSV mengadakan sesi apresiasi kepada pelajar pada penamat sesi PdPc agar pelajar dapat menghargai karya dan dapat memberi pandangan serta idea terhadap karya rakan-rakan dalam bilik darjah.

"penamatan selalunya buat apresiasi, selalunya pelajar dah siap buat memang pelajar akan bentangkan kat depan ni, selalunya memang by kumpulan la, tapi kalau mengikut kehadiran kalau dah kurang kita buat seorang-seorang la" GCPSV3

"bila sesi apresiasi tu saya tunjukkan kawan-kawan dia punya, tunjukkan la kesalahan yang kawan-kawan dia buat secara tak langsung." - GCPSV4 
"bila dah siap tu saya biasa buat saya kumpul hasil karya budak lepas tu saya panggil mana yang terbaik tu dia explained kat depan, apa yang... sama-sama ni la sesi apresiasi ada la tapi tak setiap minggu la sesekali." - GCPSV1

"kalau dah habis bahagian tu saya akan buat kritikan seni la apresiasi la, kadangkadang budak marah juga cikgu malu kenapa cikgu tunjukkan tu? tak dari sini kita kan dapat tengok kelemahan dan kekuatan hasil tu kan"- GCPSV 5

\title{
Sesi Apresiasi
}

Kebersihan bilik darjah adalah antara perkara yang dipertimbangkan dalam PdPc oleh GCPSV sebelum, semasa dan selepas PdPc adalah soal kebersihan bilik darjah dan keselamatan pelajar dalam bilik darjah:

\author{
"kebersihan, kekemasan ha itu la benda-benda." - GCPSV1 \\ "lepas tu keselamatan," - GCPSV1
}

Sebagai rumusan, didapati bahawa GCPSV menekankan amalan membuat sesi aprisiasi semasa menutup PdPc di dalam bilik darjah. Amalan ini akan dapat menggalakkan pelajar untuk lebih kreatif dan kritis dalam menghasilkan karya mereka. GCPSV juga akan memberhentikan PdPc 10 minit lebih awal supaya pelajar dapat mengemas semula bilik darjah seperti asal. Amalan mengadakan sesi aprisiasi telah membantu pelajar menguasai kemahiran GCPSV.

\section{Amalan Penilaian PdPc}

Dapatan kajian menunjukkan GCPSV mengamalkan penilaian PdPc di dalam bilik darjah. Antara amalan penilaian PdP merupakan satu aspek penting yang dapat menimbulkan: refleksi guru dan ketelitian penyemakan buku latihan dan karya pelajar.

Contoh petikan temu bual yang menunjukkan GCPSV ini membuat refleksi PdPc di bilik darjah dan penyemakan buku latihan dan karya pelajar selepas mengajar adalah seperti berikut:

\author{
"refleksi untuk hari ni saya tulis dalam rph". Nanti minggu depan saya refer balik \\ refleksi tu untuk buat rph minggu seterusnya." - GCPSV3 \\ “...buku tulis, buku lakaran lukisan.semua kena hantar pada penolong kanan \\ untuk semakkan”. - GCPSV2
}

Hasil dapatan pemerhatian dan analisis dokumen dengan GCPSV pula mendapati, sememang sudah menjadi tugas mereka untuk menilai prestasi pelajar agar mereka tidak menjalankan tugas secara sambil lewa. Hasil dapatan daripada pemerhatian dan analisis dokumen menunjukkan terdapat penulisan refleksi GCPSV di dalam bahagian buku rancangan mengajar. Analisis dokumen pula menunjukkan ketelitian penyemakan buku latihan pelajar dan ditandatangani dalam buku latihan pelajar. Hasil dapatan pemerhatian dan analisis dokumen menunjukkan pelajar dinilai berdasarkan kepada ujian atau peperiksaan yang dijalankan oleh pihak sekolah. Ujian diadakan tiga bulan sekali bagi menguji tahap pencapaian pelajar dalam setiap topik yang diajarkan oleh GCPSV dalam bilik darjah. Bagi pelajar yang mengalami masalah dalam pelajaran, mereka tidak diberikan ujian khas berdasarkan tahap yang dapat dicapai oleh mereka. Kebanyakan pelajar didapati lemah dalam mata pelajaran PSV disebabkan oleh mereka tidak mempunyai kemahiran dan pengetahuan dalam isi pengajaran GCPSV. Walau bagaimanapun, hasil dapatan pemerhatian dengan GCPSV menunjukkan pelajar dinilai berdasarkan kepada penilaian formatif, iaitu penilaian yang dibuat secara berterusan bagi menilai keberkesanan PdPc GCPSV. Penilaian tersebut dijalankan untuk mengesan sejauh manakah penguasaan pelajar selepas topik-topik selesai diajar oleh GCPSV. Sebagai kesimpulan, GCPSV perlu melakukan amalan penilaian PdPc kerana dapat menjadi refleksi guru dan mengekalkan tahap ketelitian semakan buku latihan dan hasil karya pelajar. 
Kajian menunjukkan bahawa GCPSV sebagai pemimpin di dalam bilik darjah menunjukkan kemampuan berjaya memastikan pelajar dinilai dengan menjalankan penilaian formatif dan sumatif yang mantap agar pencapaian mereka dapat diukur. Dapatan kajian menunjukkan keputusan dari penilaian yang dijalankan telah dibuat post-mortem dalam mesyuarat jawatankuasa kurikulum sekolah bagi mengenal pasti punca kelemahan pelajar dalam menguasai topik-topik mata pelajaran PSV. Langkah-langkah yang dijalankan oleh pihak sekolah ialah kelas pemulihan kemahiran melukis dan mewarna. Namun begitu dari segi pelaksanaan kedua-dua jenis kelas penilaian oleh GCPSV tidak dijalankan mengikut tahap keupayaan pelajar itu sendiri. Hal ini adalah kerana soalan-soalan ujian, peperiksaan atau pentaksiran yang dibentuk berunsur holistic dalam kalangan pelajar yang menuntut pada tingkatan yang sama. Pelajar tidak dinilai dengan tahap peningkatan secara individu tetapi secara holistic. Langkah tersebut telah menyebabkan pelajar terus gagal dalam penilaian. Menurut Magdeline dan Zamri (2016) pelajar yang pelbagai tahap pencapaian di dalam sebuah bilik darjah pula menimbulkan masalah bagi penyediaan kertas ujian.

\section{Faktor-faktor yang mempengaruhi PdPc}

Dalam temu bual yang dijalankan, pengkaji mendapati guru PSV menyediakan perancangan pengajaran dengan mengambil kira faktor-faktor yang mempengaruhi perancangan pengajaran seperti objektif yang ingin dicapai oleh guru pada PdPc hari itu, kemahiran sedia ada pelajar dan hasil karya pelajar.

\section{Pengetahuan dan kemahiran sedia ada pelajar}

Berbeza pula dengan GCPSV4, perkara yang perlu diambil kira dalam PdPc adalah kemahiran pelajar.

"biasa saya buat, budak ada yang okay dan tak okay kan kalau kita tengok budak yang okay tu dia buat dengan sendiri kita akan beri dia motivasi la kepada dia, okay bagus, tapi kita asah la lagi basic dia macam tu la okay awak color felt color jangan campur banyak color, macam tadi budak tu nak campur color banyakbanyak saya kata jangan nanti ko feed up nak buat, ikut kemampuan dia la kalau budak boleh color ton tu, saya suruh dia buat ton, tapi kalau budak sains yang buat tu ha memang semula jadi. tapi tahun ni tak ada yang buat, kalau budak seni bagi dia color je la." - GCPSV4

Trangulasi melalui pemerhatian dan dokumen karya pelajar mendapati GCPSV3, GCPSV4 dan GCPSV5 memang menekankan hasil karya dan kemahiran pelajar. GCPSV1 walaupun menekankan objektif pengajaran, di akhir sesi PdPc mendapati hasil karya dan kemahiran juga ditekankan kepada pelajar.

\section{Dokumen rujukan sewaktu membuat perangangan pengajaran}

Melalui dokumen didapati guru-guru PSV menggunakan dokumen rujukan seperti sukatan mata pelajaran PSV tingkatan 4 dan 5, rancangan pengajaran mingguan,rRancangan pengajaran harian, buku-buku rujukan dan buku-buku amali untuk membuat perancangan pengajaran.

\section{Objektif}

Bagi GCPSV1 objektif pengajaran perlu dicapai pada sesuatu sesi PdPc.

“objektif, aktiviti budak tu sepanjang PdPc buat apa kan,” - GCPSVI

\section{Hasil karya pelajar (tingkatan 5)}

Bagi GCPSV3 dan GCPSV5 pula, perkara yang perlu diambil kira dalam PdPc adalah hasil kerja pelajar. 
"saya ambil kira tentang hasil tu biasanya nak tengok kekemasan, maksudnya pelajar tu menghayati seni catan, bukanya nak buat tu asal siap walaupun tak siap tapi dia ada cara teknik dia tu, kemas, dia dapat menguasai tajuk” - GCPSV3

"yang ditekan dekat situ saya nak hasilan kerja pelajar tu la sekurang-kurangnya apa yang di buat, ikut tajuk la bila ni tak tersasar sangat la, okay bila kita kata hasilkan catan berdasarkan buah-buah tempatan, biar la dia hasilkan buah tempatan walaupun tak cantik, tak ada rupa mana tapi sekurang-kurangnya buahbuahan tempatan bukan campur epal, anggur ha macam tu la" - GCPSV5

GCPSV 3 dan GCPSV5 mengutamakan hasil karya pelajar dalam PdPc memandangkan guru-guru ini mengajar di tingkatan 5 iaitu kelas yang menduduki peperiksaan SPM. Pelajar-pelajar perlu menyiapkan kerja khusus dalam tempoh yang diberi oleh Lembaga Peperiksaan.

\section{Penyediaan alat bantu mengajar (ABM) dalam kalangan GCPSV amat dititik beratkan dalam PdPc}

Bagi GCPSV5 dalam temu bualnya mendapati beliau tidak begitu menyediakan ABM dalam persiapan mengajar. Cukup dengan ABM yang telah tersedia di dalam bilik Seni sekolah.

"kadang-kadang kita tak ada prepare mana, cumanya dari segi bahan-bahan yang ada dekat sekolah la, dari segi carta-carta bergambar la." - GCPSV5

Berlainan dengan GCPSV1 menyediakan sendiri ABM untuk persediaan mengajar PSV.

"persediaan sebelum mengajar first sekali saya akan buat bahan bantu mengajar dulu, saya sendiri buat contoh jadi bila dalam kelas tu saya letak dekat whiteboard saya sendiri buat bahan tu, ada juga la kadang tu saya ambil la dari apa yang carta ke apa saya bawa" - GCPSV1

GCPSV5 akan membuat persediaan ABM carta-carta untuk mengadakan demonstrasi kepada pelajar. Beliau akan menyediakan hasil karya catan untuk dipamerkan kepada pelajar. Melalui karya catan tersebut pelajar akan melalui pembelajaran PSV dengan penerangan daripada guru dan soalan-soalan yang di ajukan

"pertama saya akan tunjukkan hasil catan yang dah sedia ada, kita paparkan dekat depan kemudian tanya kepada pelajar agak-agak media apa yang dia gunakan, kebanyakan ramai yang lemah la kan lepas tu watercolor even poster color tu sebenarnya berbeza kan water color kan tapi yang dia tahu water color, jadi daripada situ baru kita terangkan la bagi dia cakap, dia terangkan apa ni dulu, tunjukkan gambar tu lepas tu kita tanya balik agak-agak tahu tak dari segi dia punya ye la dari segi realistik ke, dari segi maknanya pengetahuan dia orang la yang dia tahu sendiri la fasal catan tu dulu”- GCPSV5

Kekangan yang sering dihadapi oleh GCPSV adalah pelajar tidak membawa alat bantu belajar dari rumah. Masalah ini akan menjadi rumit apabila peralatan untuk PdPc pada hari tersebut tidak cukup untuk diagihkan.

"kesulitan satu dari segi alat bahan tu la kalau budak tak bawak kita kena bawa, satu lagi dia majoriti budak sekarang ni nak kita yang buat," - GCPSV1

\section{Ingatkan Pelajar Membawa Bahan Seminggu Awal}

GCPSV3 dan GCPSV2 sering mengingatkan pelajar membawa bahan seminggu awal dari sesi PdPc. 


\begin{abstract}
“minggu sebelum tu dah memang pesan kepada pelajar, minggu depan kita belajar catan lepas tu bawa barang yang sepatutnya, kalau pelajar tak bawa tu memang bilik seni akan sediakan la, sediakan barang-barang untuk mencatan tu." GCPSV3
\end{abstract}

"makanya kelas seminggu sebelum tu kita dah kena remained dia apa bahan, minggu depan kita nak buat catan bagi tahu dia ini-ini memang kena tulis dalam buku note. so minggu depan senang dia orang bawa je bahan." - GCPSV2

\title{
Persediaan ilmu PSV
}

GCPSV5 juga akan bersedia dengan penerangan yang akan disampaikan kepada pelajar.

\begin{abstract}
"okay bila dah habis tu baru la masuk penerangan, saya terangkan balik dia gunakan apa, media apa, apa dia punya bidang dia la bagaimana, ye la dia sebenarnya catan sendiri pun walaupun kita tengok catan macam tu dia masih lagi boleh dikategorikan bahagian ilustrasi, bahagian lukisan kan, even dia orang nampak benda tu semua dia orang tak akan sebut catan, dia orang sebut lukisan, jadi bila kita terangkan balik kita terangkan kepada tajuk ha baru la dia faham, catan tu sendiri asal daripada mana"
\end{abstract}

GCPSV perlu menggunakan bahan bantu mengajar PdPc seperti bahan cetak, modul, bahan elektronik, buku latihan, set mewarna seperti warna air, berus, palet dan sebagainya. Kekangan-kekangan menggunakan ABM dalam PdPc perlu ditangani dengan cara berhemah bagi melancarkan proses PdPc dalam bilik darjah. Semua peserta kajian GCPSV menyatakan pandangan mereka tentang aspek PdPc GCPSV di dalam bilik darjah yang bersesuaian dengan tahap kemahiran pelajar bagi memudahkan mereka mengikuti pelajaran yang diajar oleh GCPSV. Antara yang dibincangkan ialah kepelbagaian strategi pengajaran dan pembelajaran yang dijalankan dalam bilik darjah bagi menarik minat pelajar dalam pembelajaran. Selain itu, penekanan tentang kebersihan dalam bilik darjah juga perlu dititikberatkan supaya GCPSV dapat mendidik pelajar nilai kebersihan dalam diri mereka. Pengajaran juga perlulah sentiasa seiringan dengan perkembangan pendidikan terutamanya yang melibatkan pelajar yang lemah. Begitu juga dengan penilaian dan amalan penutup yang turut menyentuh mata pelajaran PSV serta kesesuaian bahan bantu mengajar tersebut dengan tahap pemikiran pelajar perlu diberi fokus.

\section{Perbincangan}

Dalam pengajaran PSV, guru dalam kajian ini peka dalam merancang pengajaran dan mengatur perancangan pengajaran dan pembelajaran untuk menarik minat pelajar. Guru mengamalkan rangsangan yang rapi, sistematik dan kreatif supaya pembelajaran tidak membosankan dan objektif pengajaran akan tercapai.

Perancangan pengajaran yang berkesan dipengaruhi dengan cara penyusunan PdPc yang baik dan teratur. Dapatan kajian mendapati guru-guru PSV menyusun dan merancang pengajaran dengan membuat persediaan dari segi penyediaan nota, alat bantu mengajar sama ada berbentuk bahan cetakan seperti carta, buku rujukan dan latihan, peralatan lukisan dan sebagainya sebelum menjalankan Pdpc dalam sesuatu tajuk. Dapatan ini tidak menyokong dapatan Sim (1986) yang menghujahkan guru tidak begitu mampu membuat perancangan yang baik tentang penggunaan bahan disebabkan kekurangan latihan penggunaan bahan. Inilah yang menjadi faktor penghalang kepada pelaksanaan pengajaran dan pembelajaran PSV yang berkesan.

Bagi guru PSV, bahan bantu mengajar seperti peralatan melukis amat penting untuk menjamin PdPc amali berjalan lancar. Contohnya GCPSV5 sebelum menamatkan pengajaran beliau mengingati pelajar untuk membawa peralatan PSV seminggu awal dari tarikh penggunaan alatan tersebut. Kemudian sehari sebelum PdPc dijalankan, sekali lagi beliau mengingati pelajar untuk membawa peralatan yang 
berkaitan. Semasa PdPc didapati pelajar membawa peralatan melukis dan kelas menjadi menarik dan terkawal. Namun begitu, keadaan ini tidak berlaku pada GCPSV3. Keadaan dalam bilik darjah agak tidak terkawal dan pelajar tidak ramai yang membawa peralatan melukis.

Dalam temu bual yang dijalankan mendapati guru PSV menyediakan perancangan pengajaran dengan mengambil kira faktor-faktor yang mempengaruhi perancangan pengajaran seperti objektif yang ingin dicapai oleh guru pada PdPc hari itu, kemahiran sedia ada pelajar dan hasil karya pelajar.

Dokumen seperti sukatan mata pelajaran PSV, rancangan pengajaran mingguan, rancangan pengajaran harian, buku-buku rujukan dan buku-buku amali dijadikan rujukan oleh guru-guru PSV untuk membuat perancangan pengajaran.

Beberapa jenis kaedah dan strategi pengajaran dan pembelajaran dalam PSV yang digunakan oleh guru-guru PSW dalam kajian untuk memastikan pelaksanaan pengajaran dan pembelajaran yang berkesan dalam bilik darjah. Di antaranya ialah pembelajaran inkuiri-penemuan, pembelajaran kontekstual, pembelajaran masteri dan teknologi maklumat dan komunikasi (ICT) dalam PdPC PSV.

Pembelajaran inkuiri-penemuan merupakan pendekatan yang mementingkan pengetahuan melalui pengalaman. Pembelajaran ini melalui aktiviti seperti eksperimen, pelajar akan mengkaji sesuatu tajuk atau perkara fenomena dan akan mencapai kesimpulan sendiri. Dalam kajian ini, dapatan kualitatif menunjukkan guru PSV menjalankan strategi pembelajaran inkuiri-penemuan dengan mengadakan projek untuk disiapkan oleh pelajar. Pelajar akan mencari maklumat, menyoal dan menyiasat sesuatu fenomena yang berlaku di sekeliling melalui aktiviti amali, projek, perbincangan dan apresiasi. Prosesproses ini berlaku semasa proses perkembangan idea sehinggalah menghasilkan sesebuah produk. Guru pula sekadar bertindak sebagai pembimbing dalam pembelajaran inkuiri-penemuan.

Selain daripada itu, guru juga mengadakan lawatan sambil belajar ke tempat-tempat yang boleh memberi input dan idea kepada pelajar seperti di balai seni negara yang dilakukan oleh GCPSV2. Berdasarkan hasil inkuiri, pelajar menggunakan kemahiran berfikir untuk membuat kesimpulan sendiri serta mencari kajian seni dan membuat kesimpulan sendiri. Aplikasi inkuiri-penemuan ini berlaku pada setiap kali guru PSV menjalankan latihan amali di dalam bilik darjah. Sebagai contonya, pelajar mempelajari tentang warna. Pelajar menguji campuran warna-warna dan mereka hasilkan berbagai warna-warna baru setiap kali warna dicampurkan pada kuantiti yang berbeza.

Dalam dapatan kajian ini juga, guru PSV didapati menggunakan kaedah pembelajaran kontekstual. Kaedah pembelajaran ini adalah pembelajaran yang menggabungkan ilmu kandungan dengan pengalaman harian individu, masyarakat dan alam pekerjaan. Teori ini menggalakkan guru memilih atau mewujudkan persekitaran pembelajaran yang merangkumi pelbagai pengalaman sama ada dalam konteks budaya, sosial, fizikal atau psikologi untuk mendapatkan hasil pembelajaran yang dihasratkan. Dalam dapatan kajian kualitatif menunjukkan kebanyakan guru-guru PSV yang ditemu bual menyatakan bahawa cara yang sering dilakukan untuk memotivasikan pelajar di dalam bilik darjah semasa PdPc adalah dengan mengaitkan mata pelajaran PSV dengan kerjaya mereka di masa hadapan. Contohnya GCPSV2 dan GCPSV5. GCPSV2 dalam aktiviti yang beliau jalankan bagi meningkatkan pencapaian pelajar ialah dengan menjemput tenaga pengajar luar dan bekas pelajar beliau yang telah berjaya dalam bidang seni untuk memotivasikan pelajar.

Guru-guru dalam kajian ini juga melakukan kaedah pembelajaran masteri. Pembelajaran ini merupakan satu pendekatan yang memastikan semua pelajar menguasai objektif pembelajaran yang ditetapkan. Pendekatan ini berpegang kepada prinsip bahawa setiap pelajar mampu belajar jika diberi peluang. Peluang perlu diberi kepada pelajar untuk belajar mengikut kadarnya. Untuk pelajar yang sanggup menguasai konsep dengan cepat, aktiviti pengayaan mengukuhkan lagi pengetahuannya. Untuk pelajar yang belajar pada kadar yang lebih perlahan, aktiviti pemulihan diberi untuk meningkatkan kadar pembelajaran. Dalam dapatan kajian melalui temu bual mendapati guru mengajar dengan mengambil kita pengetahuan sedia ada pelajar. Pelajar yang lemah akan diberi penumpuan yang lebih oleh guru dengan memberi satu contoh karya dan pelajar membuat aktiviti secara individu. Sementara pelajar 
yang pandai dan sederhana pula aktiviti melukis biasanya dilakukan secara berkumpulan. PdPc juga adalah mengikut kesesuaian dan kesediaan pelajar sendiri.

Pembelajaran melalui penggunaan Teknologi Maklumat dan Komunikasi (ICT) dalam PdPc PSV membolehkan pelajar mengakses data dan maklumat untuk memperluaskan pengetahuan dan kemahiran selain bahan cetak yang konvensional. Dapatan kajian melalui pemerhatian dan temu bual mendapati Pembelajaran ini diaplikasikan oleh guru dalam PdPc PSV melalui projek kolaboratif dengan menggunakan komputer melalui penyelidikan mencari bahan melalui internet dan mengkaji sesuatu bahan seni menggunakan ICT dan sebagainya. Namun begitu penggunaannya belum lagi mencapai tahap yang memberangsangkan kerana penggunaan ICT hanya tertumpu kepada mencari maklumat untuk projek yang perlu disiapkan. Seharusnya penggunaan ICT lebih meluas lagi kerana ICT telah lebih 20 tahun diperkenalkan di sekolah melalui projek sekolah bestari pada tahun 1997. Dasar Wawasan 2020 telah memacu penggunaan ICT dengan meluas dalam pendidikan negara melalui pelancaran projek Koridor Raya Multimedia pada tahun 1997 melalui Projek Sekolah Bestari. Pelbagai usaha membudayakan ICT juga telah diperkenalkan di sekolah bagi merapatkan jurang digital yang dihadapi oleh negara berbanding negara maju. Projek Makmal Komputer yang dilengkapi dengan komputer terkini berserta kemudahan LAN dan Internet mula dilaksanakan pada tahun 1999. Seharusnya penggunaan ICT di sekolah lebih rancak lagi digunakan di sekolah, tetapi sebaliknya hanya sebahagian guru sahaja yang merancakkan penggunaan ICT di sekolah. Dapatan kajian ini menyokong dapatan Mohd. Nor Bakar (2011) yang menyatakan rekod penyelenggaraan yang dijalankan di sebuah sekolah menunjukkan rekod penggunaan pada tahap yang rendah. Rosnaini (2011) juga menyatakan pendapat yang sama iaitu dalam kajian berkaitan penggunaan ICT dalam kalangan guru di sekolah, menunjukkan tahap yang rendah walaupun ICT telah diperakui mempunyai pelbagai kelebihan, namun tahap penerimaan pengguna khususnya guru terhadap inovasi tersebut didapati masih berbeza-beza.

Selain daripada itu, strategi pengajaran yang diamalkan oleh guru dalam kajian ini adalah dengan melakukan pengajaran dengan strategi berbentuk Kajian masa depan. Melalui strategi ini pelajar digalakkan menggunakan pemikiran kritis dan kreatif untuk meninjau perubahan keadaan dari masa dahulu ke masa sekarang, dan seterusnya membuat ramalan tentang keadaan yang mungkin berlaku pada masa depan. Pedagogi ini berpusatkan pelajar dan menggabungjalinkan PSV dengan pelbagai bidang yang lain seperti pendidikan alam sekitar, sains, dan lain-lain.

Penambahbaikan secara berterusan perlu dalam menjalankan aktiviti dan kaedah pengajaran dalam mata pelajaran PSV. Amalan penambahbaikan terhadap pelajar yang sering dilakukan oleh guru PSV adalah dengan menjadikan mata pelajaran PSV mudah bagi pelajar untuk dipelajari, guru sebagai pembimbing haruslah mempunyai kemahiran menarik perhatian pelajar dengan menunjukkan keindahan dalam seni itu sendiri. GCPSV1 dan GCPSV5 menekankan Kemahiran asas sebagai cara mengatasi kesukaran pelajar untuk belajar. Penambahbaikan Berterusan terhadap Guru pula adalah walaupun guru psv dalam kajian ini adalah terdiri daripada guru cemerlang, namun kursus dan bengkel sering dihadiri oleh mereka sebagai penambahbaikan secara berterusan kerana ia banyak memberi kesan yang positif kepada corak pengajaran dan pembelajaran guru-guru. Mereka dapat berkongsi kemahiran sesama guru. Dengan cara sebegini guru-guru akan dapat membaiki dan menambah baik corak pengajaran dan kemahiran sedia ada guru PSV. Contohnya GCPSV4 mempelajari kemahiran yang berbeza dari kemahiran sedia ada beliau semasa menghadiri kursus dan bengkel PSV.

\section{Kesimpulan}

Dapatan kajian mendapati GCPSV dalam kajian ini merupakan seorang yang berpengalaman, ketua panitia dan juga ketua bidang. GCPSV mampu menyampaikan ilmu PSV di dalam bilik darjah yang bersesuaian pendekatan, kaedah serta teknik pengajaran bagi menarik minat pelajar mengikuti pelajaran yang diajar oleh mereka. GCPSV perlu bergerak seiringan dengan perkembangan corak PdPc di dalam bilik darjah. Dapatan kajian ini sejajar dengan kajian Misnan (2008) mendapati untuk menjadi seorang guru yang berkesan, sama ada dari segi menyampaikan ilmu pengetahuan atau sesuatu kemahiran, maka seseorang guru itu hendaklah memahami konsep pendekatan, kaedah, teknik dan strategi yang bersesuaian dalam masa yang sama dapat mewujudkan suasana pembelajaran yang 
DOI: https://doi.org/10.47405/mjssh.v5i5.394

harmonis, menyenorokkan dan tidak membosankan. Menurut Magdeline dan Zamri (2016) guru yang mengkhusus dalam bidangnya sudah tentu mempunyai pengetahuan pedagogi kandungan yang lebih baik berbanding guru yang bukan bidang, tetapi mengajar mata pelajaran yang sama. Guru yang mempunyai pengkhususan sudah tentu dapat mengajar dengan baik. Guru tersebut lebih mengetahui isi kandungan kurikulum yang diajar. Rumusannya untuk menjadi GCPSV, seseorang guru perlu memiliki ilmu dan pengalaman ilmu yang mantap. GCPSV perlu sanggup menyampaikan PdPc secara berkesan dengan mengambil kira kepelbagaian kecerdasan pelajar. Ilmu dan pengalaman ilmu GCPSV dapat dilaksanakan secara holistik apabila pelajar sanggup menerima pengajaran GCPSV dan pembelajaran pelajar secara berterusan.

\section{Rujukan}

Ainon Wazir \& Nik Rahimi Nik Yusof. (2013). Pengetahuan Isi Kandungan Bahasa Arab Dalam Kalangan Guru Sekolah Rendah: Satu Tinjauan Awal, seminar kebangsaan penyelidikan J-Qaf (2013) SKPj-QAF 2013)

Ainon Wazir. (2016). Pengetahuan Pedagogi Isi Kandungan Guru Bahasa Arab Sekolah Rendah, Tesis Dr. Fal, Fakulti Pendidikan, Universiti Kebangsaan Malaysia.

Aisah Binti Hasmam. (2017). Amalan Guru Cemerlang Bahasa Arab Dalam Pengajaran Kosa Kata Peringkat Menengah Rendah Tesis Dr. Fal, Fakulti Pendidikan, Universiti Kebangsaan Malaysia.

Choong, L. K. (2009). Falsafah Dan Pendidikan Di Malaysia Untuk Kursus Perguruan Pendidikan Rendah Pengajian Empat Tahun. Subang Jaya: Kumpulan Budiman Sdn.Bhd.

Chow, F. M. (2005). Jendela kelabu: Pendekatan kualitatif dalam kajian tindakan. Kertas kerja yang dibentangkan dalam Seminar Penyelidikan Tindakan. Batu Pahat, Johor, 25-27 September.

Cresswell, J.W. (2018). Research Design: Qualitative, Quantitative, and Mixed Methods Approaches 5th Edition, Kindle Edition Sage Publication.

Cohen, D.K. (1986). Assessing the Quality of Teacher Education. East Lansing, MI: National Center for Research on Teacher Education

Merriam, S.B. (2009). Qualitative Research: A Guide to Design and Implementation: JOSSEY-BASS A Wiley Imprint

Magdeline Anak Nor, (2014). Teras Pengetahuan Dan Pedagogi Guru Bahasa Iban Sekolah Menengah Di Sarawak. UKM Bangi.

Magdeline Anak Nor \& Zambri Mahmud (2016). Teras Pengetahuan Dan Pedagogi Guru Bahasa Iban Sekolah Menengah Di Sarawak. UKM Bangi

Nurul Hudaa Hassan. (2005). Persepsi guru-guru Program Khas Pensiswazahan Guru (PKPG) Bahasa Arab MPI-UIAM terhadap ilmu nahu. Projek Penyelidikan Sarjana Pendidikan, Fakulti Pendidikan, Universiti Kebangsaan Malaysia.

Ong, S.C., Zambri \& Mohd Izham (2017). Meneroka Kaedah Pengajaran Guru Cemerlang PSV Negeri Sarawak: Satu Kajian Kes. Jurnal pendidikan PSV Vol.7, Bi. 1 (Mei 2017).

Taylor, S.J. \& Bogden, R. (2015). Introduction to Qualitative Research Methods: A Guidebook and Resource, $4^{\text {th }}$ Edition: New York: John Wiley \& Sons.

Yin, R. K. (2014). Case Study Research: Design and Methods. Beverly Hills, CA: Sage. 